\title{
Tannic Acid Induces Apoptosis In Bladder Cancer Cells Via Mitochondrial-Dependent And AKT Pathway
}

\section{Ming-Cheng Chen}

Taichung Veterans General Hospital

\section{Ann Seles S}

Hualien Tzu Chi Hospital

Bharath Kumar Velmurugan ( $\square$ bharath.kumar.velmurugan@tdt.edu.vn )

Asia University https://orcid.org/0000-0002-4786-9913

\section{Chiung-Hung Hsu}

Hualien Tzu Chi Hospital

\section{Cecilia Hsuan Day}

Meiho University

\section{Ray-Jade Chen}

Taipei Medical University

\section{Tso-Fu Wang}

Hualien Tzu Chi Hospital

Vijaya Padma Viswanadha

Bharathiar University

\section{Chi-Cheng Li}

Hualien Tzu Chi Hospital

Chih-Yang Huang

Hualien Tzu Chi Hospital

\section{Research Article}

Keywords: TA, UMUC3, SOX2, NANOG, bladder cancer

Posted Date: September 14th, 2021

DOl: https://doi.org/10.21203/rs.3.rs-816405/v1

License: (c) (1) This work is licensed under a Creative Commons Attribution 4.0 International License.

Read Full License 


\section{Abstract}

Urothelial bladder cancer is rapidly spreading across Western countries, and therapy has shown little-tomoderate effects on bladder cancer. Thus, focusing on curbing cancer incidence has become crucial. In this study, we examined the effects of tannic acid, a polyphenol with anti-fungal and anti-cancer effects, on UMUC3 bladder cancer cells. UMUC3 cells were exposed to tannic acid for 24 hours, following which we observed significant inhibition of cell proliferation. Additionally, flow cytometry and TUNEL assay revealed that tannic acid induces apoptosis in UMUC3 cells in a dose-dependent manner. Furthermore, tannic acid treatment upregulated the expression of cleaved caspase-3 which further confirmed induction of apoptosis in UMUC3 cells by treatment with tannic acid. TA treatment decreased stem cell markers expression such as SOX2, OCT4, and NANOG. Together, these results showed that tannic acid can promote apoptosis; therefore, it may have potential as treatment for bladder cancer.

\section{Introduction}

Bladder cancer is the commonest cancer in the Western world; it is more prevalent in men than in women, but it is usually detected in women at a late or advanced stage [1,2]. There are two types of bladder cancer: most cases are of the non-muscle invasive (NMIBC, $>70 \%$ ) type, which are locally treated and have recurrence rate, whereas the other type is muscle-invasive bladder cancer (MIBC) that can develop into advanced tumors and usually shows poor stability. Treatment of MIBC involves radiation therapy or bladder removal [3]. Tobacco smoking is considered to be one of the main causative agents that is known to elevate the risk of bladder cancer [4]. Other factors include environmental conditions, diet, occupation, and fewer medical conditions such as genetic disorders [5]. Radical cystectomy is the most prevalent surgery performed in bladder cancer patients to prevent malignancy. However, adjuvant chemotherapy was found to be effective in patients with local MIBC alone [6].

Recently, compounds derived from plants are being utilized in the United States and Europe for treating cancer [7]. These compounds play a role during the initial stage and delay the process of cancer cell transformation, and some are known to inhibit metastasis. These natural products are inexpensive, easily available and are not associated with any adverse effects when used for treating patients [8,9]. Phenolic compounds are studied in a variety of cancers as they block cancer cell growth and arrest metastasis [10].

Tannic acid (TA) is a water-soluble, polyphenol compound present in plants, wine, nuts and fruits [11]. Tannins, also known as TA, are known to have anti-mutagenic and anti-microbial properties [12, 13]. Studies have shown that TA improves the effect of doxorubicin-induced anti-cancer activity in breast cancer cells [14], and can ameliorate cisplatin reactivity in ovarian cancer cells when treated along with cisplatin [15]. Literature reveals that treatment with TA can hinder invasion and proliferation in prostate cancer cells via endoplasmic reticulum stress-inducing apoptosis [11]. The tumor inhibiting properties of TA is widely studied in various cancer cells $[16,17]$. In this study, we speculate that TA can inhibit bladder cancer incidence by inducing apoptosis in MIBC cells. 


\section{Methods}

\subsection{Cell lines and reagents}

Two cell lines were used in this study, namely, the normal urinary bladder cell line SV-HUC1 (Ham F-12K nutrient mixture) and and UMUC3-Grade III transitional cell carcinoma (EMEM media).

\subsection{MTT assay}

The UMUC3 cell line was plated in a 24-well plate with 50,000 cells per well and was left for attachment. After the cells were well attached to the plate, the cells were washed with phosphate-buffered saline (PBS), following which they were treated with TA at different concentrations and allowed to incubate at different time points. Next, $1 \mathrm{~mL}$ of MTT was added, and the plate was kept again for incubation. After 1 hour, MTT was removed and $500 \mathrm{~mL}$ of dimethyl sulfoxide (DMSO) was placed in a shaker for 5-10 minutes. Optical density (OD) was measured at $570 \mathrm{~nm}$ and the graph was subsequently plotted [18].

\subsection{Colony formation assay}

We seeded 500 cells of UMUC3 in a 6-well plate and incubated them for 24 hours. The cells were then treated with different concentrations of TA and the plate was kept in the incubator for another 24 hours. Subsequently, the media was removed, they were washed twice with PBS, and normal culture media was added. The cells were then allowed to grow for 14 days, during which the culture media was changed every 2 days. After 14 days, the colonies were photographed using a microscope and the cell colonies were counted in each condition.

\subsection{Flow cytometry}

Cells were seeded 24 hours before treatment with TA at different concentrations, following which the plates were kept in the incubator for another 24 hours. Then, the cells were washed with PBS. Next, the cells were collected, the supernatant was discarded, the cell pellet was washed, and 100,000 cells were then taken in $100 \mu \mathrm{L}$ of binding buffer in a flow tube. Then, $5 \mu \mathrm{L}$ of FITC stain and $5 \mu \mathrm{L}$ of propidium iodide was added and kept in the dark for 15 minutes. Finally, $400 \mu \mathrm{L}$ of binding buffer was added to each sample and analyzed using FACS Cell quest program.

\subsection{Western blot}

UMUC3 cells were seeded in 6-well plates. After cell attachment, TA was treated for 24 hours and the protein was extracted using RIPA lysis buffer [19]. Protein was then quantified using Bradford's method. The protein was loaded in $8-12 \%$ gel, and then transferred to the PVDF membrane. Next, $5 \%$ milk powder in $1 \times$ TBST was used for blocking the membrane for 1 hour. The membrane was probed with primary antibodies overnight, washed with $1 \times$ TBST, and probed with respective secondary antibodies for 1 hour at room temperature [20]. Enhanced chemiluminescence solution was then used for visualization, and protein expression was analyzed. 


\subsection{TUNEL assay}

Cancer cells were seeded in glass slides at $70 \%$ confluence and were allowed to rest for 24 hours for cell attachment. The media was removed, and the cells were washed twice with $1 \times$ PBS. TA was added to the cells at different concentrations, it was then incubated for 24 hours. After treatment, the media was removed and washed with $1 \times$ PBS twice. Cell samples were then fixed with $4 \%$ paraformaldehyde, dissolved in PBS for 1 hour, washed with PBS twice, followed by incubation in permeabilization solution for 2 minutes following Roche's in situ hybridization protocol. Then, the samples were again washed with PBS and stained with TUNEL reaction mixture, and incubated for 1-3 hours. Then, the slides were washed, stained with DAPI, and analyzed. The TUNEL-positive cells were counted in nuclei compared to the control.

\section{Results}

\subsection{Tannic acid inhibited cell proliferation in bladder cancer cells}

Cells were treated with TA at different concentrations $(0 \mu \mathrm{M}, 25 \mu \mathrm{M}, 50 \mu \mathrm{M}, 100 \mu \mathrm{M}, 200 \mu \mathrm{M})$ for 24 hours. Compared to untreated cells, TA treated cells dose dependently decreased UMUC3 cell growth (Figure 1a). Treatment with TA showed high toxicity in UMUC3 cells, and the growth inhibition was evident from lower concentration. In the normal urinary cells -SV-HUC1, TA treatment did not show any significant changes in cell proliferation (Figure 1b).

When UMUC3 cells were treated with TA and observed after incubation for 14 days, it was found that, compared to the control cells, the treated cells had significantly reduced number and size of colonies, and this variation was dose dependent. These results indicated that TA can inhibit colony formation in UMUC3 cells.

\subsection{Tannic acid induced apoptosis in UMUC3 cells}

After treatment of UMUC3 cells with different concentrations of TA for 24 hours, the cells were collected and analyzed to check whether TA induced apoptosis in cancer cells. As shown in Figure 2, treatment with TA induced apoptosis in a dose-dependent manner in UMUC3 cells. This data confirmed that TA inhibits proliferation of cancer cells by promoting apoptosis. To further validate the effects of TA, TUNEL assay was performed and analyzed for TUNEL-positive cells while treated with TA. As expected, the number of TUNEL-positive cells were found to be higher when the cells were treated with TA (Figure 3). Therefore, cancer cells exhibited higher rates of apoptosis when treated with TA.

\subsection{Tannic acid promoted apoptosis through the intrinsic mitochondrial pathway}

As TA elevated the occurrence of apoptosis in UMUC3 cells, we checked whether apoptosis was regulated by the intrinsic or extrinsic pathway. We first analyzed the caspase-3 pro- and cleaved- form in UMUC3 cells after treating the cells with TA for 24 hours. We found that the expression of the cleaved-form of 
caspase-3 was remarkably higher in cells treated with higher concentrations of TA, while the pre-form was reduced in a dose-dependent manner (Figure 4).

We also checked the protein expression of the Bcl-2 family (anti-apoptotic) proteins such as Bcl-2, Bcl-xL and $\mathrm{Mcl}-1$, which are important for regulating cell survival. These protein expressions were significantly downregulated after treatment with TA, which further proved that the cells were affected due to TA treatment.

\subsection{Tannic acid affected the stemness of UMUC3 cells}

TA promoted apoptosis in UMUC3 cells and also reduced the colony-formation ability of the cancer cells. Therefore, next, we investigated whether TA treatment has any effects on the expression of stem cell markers. As expected, we found that TA treatment lowered the expression of stem cell markers such as SOX2, OCT4, and NANOG protein expression in a dose-dependent manner. Thus, TA was found to be effective to block the proliferation of cancer stem cells (Figure 5).

\subsection{Tannic acid promoted apoptosis in UMUC3 cells through PI3K/AKT pathway}

As the PI3K/AKT pathway plays a very important role in proliferation activity, we then analyzed whether AKT protein level is altered after TA treatment. As shown in Figure 6, phosphorylation level of AKT was lowered in a dose depend manner Additionally, we found that total AKT did not show any significant changes. These results showed that TA can inhibit the proliferation of UMUC3 cells via AKT pathway.

\section{Discussion}

Bladder cancer incidence increases progressively and usually shows recurrence in cases of late-stage MIBC [3], and therefore it is important to examine the exact mechanism of cancer development and successfully inhibit disease progression. Recently, studies reported an effective outcome of Chinese herbal compounds that are known to reduce cancer threat. Moreover, in regard to conventional cancer treatment, research in the United States bureau reports a suspected increase in the cost of cancer treatment as cancer cases are on the rise in recent years [21].

Non-steroidal anti-inflammatory drugs (NSAIDs) are majorly used in different countries for the treatment of bladder cancer. However, a study reported that NSAIDs are known to be effective only in bladder cancer patients who are non-smokers [22, 23]. As smoking contributes to an enormous number of cancer cases in men and women, several studies are being conducted on this subject to lower the cancer risk and prevent cancer occurrence. A study also showed that quitting smoking decreased the severity of bladder cancer in post-menopausal women [24, 25].

Another study revealed that TA can act as an anti-oxidant to reduce stress conditions in the brain tissue of rats to ameliorate ischemia [26] and in various types of cancers [16, 17]. TA combined with other drugs also showed significant induction of apoptosis in colon adenocarcinoma cells [27]. To the best of our knowledge, this is the first study to show the anti-cancer effects of TA against human invasive bladder 
cancer cell lines. In the present study, TA inhibited proliferation and promoted apoptosis in a dosedependent manner. Flow cytometry and TUNEL assay were performed to confirm the effects of TA in bladder cancer cells.

Apoptosis is an important event that helps to reduce the incidence of cancer. Studies conducted on different types of diseases speculate that drugs can be effective if they successfully target apoptosis. Caspases and the Bcl-2 protein family are major factors considered in the apoptosis of cancer cells [28]. In this study, caspase-3 was activated during treatment with TA in bladder cancer cells, and we observed reduced Bcl-2 levels, which further proves that TA can induce apoptosis through the intrinsic mitochondrial pathway. The above results suggest that TA can be potentially used as a therapeutic drug to treat bladder cancer.

Cancer stem cells are a subset of cells that are implicated in tumor initiation and progression to metastasis. Recently, many studies focus on inhibiting cancer stem cell properties to block cancer progression [29]. By analyzing cancer stem cell markers, we confirmed that TA was able to reduce their colony-formation ability along with reducing the expression of SOX2, OCT4, and NANOG, which are important markers that indicate cancer cell stemness. This shows that TA can act against cancer stem cells without affecting the normal cells.

In gingival cancer cells, TA, at a concentration of $60 \mu \mathrm{M}$, promoted cell cycle arrest in the $\mathrm{G} 1$ phase by modulating the phosphorylation of STAT3 and JAK2 proteins [30]. The compound also altered the STAT1/3 and EGF-R pathways to reduce cell multiplication and induce apoptosis in breast cancer cells [31]. In this study, TA inhibited proliferation and induced apoptosis in UMUC3 bladder cancer cells by altering the AKT pathway in a dose-dependent manner.

In conclusion, we have proved that TA can be used in the treatment of bladder cancer as it has been proven to be effective in blocking cancer stemness. Additionally, the drug was able to effectively cause a significantly high percentage of apoptosis in high grade bladder cancer cells, which can be beneficial for humans in cases of recurrence or advance-stage bladder cancer.

\section{Declarations}

Conflict of Interest: All the authors declared that they have no conflict of interest.

Acknowledgment: This work was supported by China Medical university and Asia University, Taiwan (CMU107-ASIA-01)

\section{Data availability statement:}

All data generated or analyzed during this study are included in this published article. Additional information is available from the corresponding author on reasonable request. 
Author Contribution : Conceptualization, M.C.C., C.Y.H methodology, A.S.S.; validation, C.Y.H., V.B.K.; formal analysis, M.C.C., C.H.H.; investigation, C.Y.H., M.C.C.; data curation, C.H.D., R.J.C.; writing-original draft preparation, V.B.K.; writing-review and editing, T.F.W., V.P.V., C.C.L.; visualization, M.C.C., C.Y.H.; supervision, C.Y.H. All authors have read and agreed to the published version of the manuscript.

\section{References}

1. Dobruch J, Daneshmand S, Fisch M, Lotan Y, Noon AP, Resnick MJ, Shariat SF, Zlotta AR, Boorjian SA (2016) Gender and Bladder Cancer: A Collaborative Review of Etiology, Biology, and Outcomes. Eur Urol 69:300-310. doi:10.1016/j.eururo.2015.08.037

2. May M, Bastian PJ, Brookman-May S, Fritsche HM, Tilki D, Otto W, Bolenz C, Gilfrich C, Trojan L, Herrmann E, Moritz R, Tiemann A, Muller SC, Ellinger J, Buchner A, Stief CG, Wieland WF, Hofner T, Hohenfellner M, Haferkamp A, Roigas J, Zacharias M, Nuhn P, Burger M (2013) Gender-specific differences in cancer-specific survival after radical cystectomy for patients with urothelial carcinoma of the urinary bladder in pathologic tumor stage T4a. Urol Oncol 31:1141-1147. doi:10.1016/j.urolonc.2011.09.011

3. Richters A, Aben KKH, Kiemeney L (2020) The global burden of urinary bladder cancer: an update. World J Urol 38:1895-1904. doi:10.1007/s00345-019-02984-4

4. Cumberbatch MG, Rota M, Catto JW, La Vecchia C (2016) The Role of Tobacco Smoke in Bladder and Kidney Carcinogenesis: A Comparison of Exposures and Meta-analysis of Incidence and Mortality Risks. Eur Urol 70:458-466. doi:10.1016/j.eururo.2015.06.042

5. Burger M, Catto JW, Dalbagni G, Grossman HB, Herr H, Karakiewicz P, Kassouf W, Kiemeney LA, La Vecchia C, Shariat S, Lotan Y (2013) Epidemiology and risk factors of urothelial bladder cancer. Eur Urol 63:234-241. doi:10.1016/j.eururo.2012.07.033

6. Kim DK, Lee JY, Jung JH, Hah YS, Cho KS (2019) Role of adjuvant cisplatin-based chemotherapy following radical cystectomy in locally advanced muscle-invasive bladder cancer: Systematic review and meta-analysis of randomized trials. Investig Clin Urol 60:64-74. doi:10.4111/icu.2019.60.2.64

7. Surh YJ (2003) Cancer chemoprevention with dietary phytochemicals. Nat Rev Cancer 3:768-780. doi:10.1038/nrc1189

8. Kapinova A, Kubatka P, Golubnitschaja O, Kello M, Zubor P, Solar P, Pec M (2018) Dietary phytochemicals in breast cancer research: anticancer effects and potential utility for effective chemoprevention. Environ Health Prev Med 23:36. doi:10.1186/s12199-018-0724-1

9. Kotecha R, Takami A, Espinoza JL (2016) Dietary phytochemicals and cancer chemoprevention: a review of the clinical evidence. Oncotarget 7:52517-52529. doi:10.18632/oncotarget.9593

10. Liskova A, Stefanicka P, Samec M, Smejkal K, Zubor P, Bielik T, Biskupska-Bodova K, Kwon TK, Danko J, Busselberg D, Adamek M, Rodrigo L, Kruzliak P, Shleikin A, Kubatka P (2020) Dietary phytochemicals as the potential protectors against carcinogenesis and their role in cancer chemoprevention. Clin Exp Med 20:173-190. doi:10.1007/s10238-020-00611-w 
11. Nagesh PKB, Hatami E, Chowdhury P, Kashyap VK, Khan S, Hafeez BB, Chauhan SC, Jaggi M, Yallapu MM (2018) Tannic Acid Induces Endoplasmic Reticulum Stress-Mediated Apoptosis in Prostate Cancer. Cancers (Basel) 10. doi:10.3390/cancers10030068

12. Chung KT, Wong TY, Wei Cl, Huang YW, Lin Y (1998) Tannins and human health: a review. Crit Rev Food Sci Nutr 38:421-464. doi:10.1080/10408699891274273

13. Ferreira D, Gross GG, Hagerman AE, Kolodziej H, Yoshida T (2008) Tannins and related polyphenols: perspectives on their chemistry, biology, ecological effects, and human health protection. Phytochemistry 69:3006-3008. doi:10.1016/j.phytochem.2008.10.018

14. Tikoo K, Sane MS, Gupta C (2011) Tannic acid ameliorates doxorubicin-induced cardiotoxicity and potentiates its anti-cancer activity: potential role of tannins in cancer chemotherapy. Toxicol Appl Pharmacol 251:191-200. doi:10.1016/j.taap.2010.12.012

15. Sun Y, Zhang T, Wang B, Li H, Li P (2012) Tannic acid, an inhibitor of poly(ADP-ribose) glycohydrolase, sensitizes ovarian carcinoma cells to cisplatin. Anticancer Drugs 23:979-990. doi:10.1097/CAD.0b013e328356359f

16. Nam S, Smith DM, Dou QP (2001) Tannic acid potently inhibits tumor cell proteasome activity, increases p27 and Bax expression, and induces G1 arrest and apoptosis. Cancer Epidemiol Biomarkers Prev 10:1083-1088

17. Karakurt S, Adali O (2016) Tannic Acid Inhibits Proliferation, Migration, Invasion of Prostate Cancer and Modulates Drug Metabolizing and Antioxidant Enzymes. Anticancer Agents Med Chem 16:781789. doi:10.2174/1871520616666151111115809

18. Lee H-P, Wang S-W, Wu Y-C, Tsai C-H, Tsai F-J, Chung J-G, Huang C-Y, Yang J-S, Hsu Y-M, Yin M-C, Li T-M, Tang C-H (2019) Glucocerebroside reduces endothelial progenitor cell-induced angiogenesis. Food Agricultural Immunology 30:1033-1045. doi:10.1080/09540105.2019.1660623

19. Lee H-P, Wang S-W, Wu Y-C, Lin L-W, Tsai F-J, Yang J-S, Li T-M, Tang C-H (2020) Soya-cerebroside inhibits VEGF-facilitated angiogenesis in endothelial progenitor cells. Food Agricultural Immunology 31:193-204. doi:10.1080/09540105.2020.1713055

20. Lee H-P, Wu Y-C, Chen B-C, Liu S-C, Li T-M, Huang W-C, Hsu C-J, Tang C-H (2020) Soya-cerebroside reduces interleukin production in human rheumatoid arthritis synovial fibroblasts by inhibiting the ERK, NF-KB and AP-1 signalling pathways. Food Agricultural Immunology 31:740-750. doi:10.1080/09540105.2020.1766426

21. Mariotto AB, Yabroff KR, Shao Y, Feuer EJ, Brown ML (2011) Projections of the cost of cancer care in the United States: 2010-2020. J Natl Cancer Inst 103:117-128. doi:10.1093/jnci/djq495

22. Daugherty SE, Pfeiffer RM, Sigurdson AJ, Hayes RB, Leitzmann M, Schatzkin A, Hollenbeck AR, Silverman DT (2011) Nonsteroidal antiinflammatory drugs and bladder cancer: a pooled analysis. Am J Epidemiol 173:721-730. doi:10.1093/aje/kwq437

23. Castelao JE, Yuan JM, Gago-Dominguez M, Yu MC, Ross RK (2000) Non-steroidal anti-inflammatory drugs and bladder cancer prevention. Br J Cancer 82:1364-1369. doi:10.1054/bjoc.1999.1106 
24. Freedman ND, Silverman DT, Hollenbeck AR, Schatzkin A, Abnet CC (2011) Association between smoking and risk of bladder cancer among men and women. JAMA 306:737-745.

doi:10.1001/jama.2011.1142

25. Li Y, Tindle HA, Hendryx MS, Xun P, He K, Liang X, Luo J (2019) Smoking Cessation and the Risk of Bladder Cancer among Postmenopausal Women. Cancer Prev Res (Phila) 12:305-314. doi:10.1158/1940-6207.CAPR-18-0441

26. Sen HM, Ozkan A, Guven M, Akman T, Aras AB, Sehitoglu I, Alacam H, Silan C, Cosar M, Ozisik Karaman HI (2015) Effects of Tannic Acid on the Ischemic Brain Tissue of Rats. Inflammation 38:1624-1630. doi:10.1007/s10753-015-0138-9

27. Cosan D, Soyocak A, Basaran A, Degirmenci I, Gunes HV (2009) The effects of resveratrol and tannic acid on apoptosis in colon adenocarcinoma cell line. Saudi Med J 30:191-195

28. Wong RS (2011) Apoptosis in cancer: from pathogenesis to treatment. J Exp Clin Cancer Res 30:87. doi:10.1186/1756-9966-30-87

29. Ayob AZ, Ramasamy TS (2018) Cancer stem cells as key drivers of tumour progression. J Biomed Sci 25:20. doi:10.1186/s12929-018-0426-4

30. Darvin P, Baeg SJ, Joung YH, Sp N, Kang DY, Byun HJ, Park JU, Yang YM (2015) Tannic acid inhibits the Jak2/STAT3 pathway and induces G1/S arrest and mitochondrial apoptosis in YD-38 gingival cancer cells. Int J Oncol 47:1111-1120. doi:10.3892/ijo.2015.3098

31. Darvin P, Joung YH, Kang DY, Sp N, Byun HJ, Hwang TS, Sasidharakurup H, Lee CH, Cho KH, Park KD, Lee HK, Yang YM (2017) Tannic acid inhibits EGFR/STAT1/3 and enhances p38/STAT1 signalling axis in breast cancer cells. J Cell Mol Med 21:720-734. doi:10.1111/jcmm.13015

\section{Figures}


$\mathbf{A}$

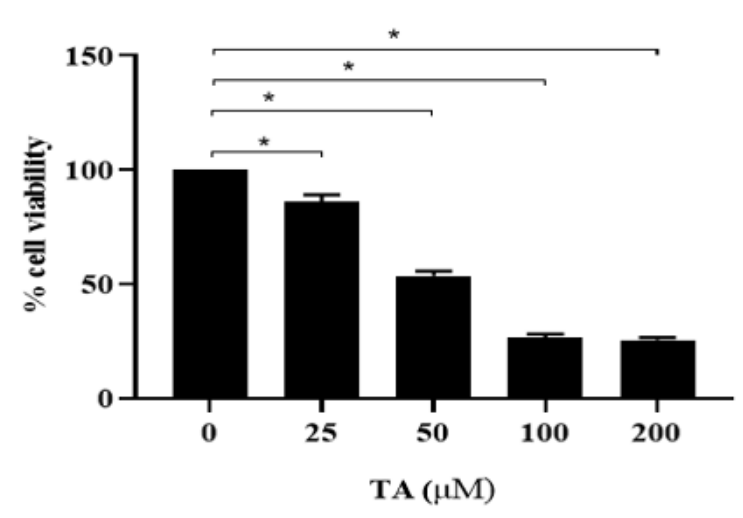

C

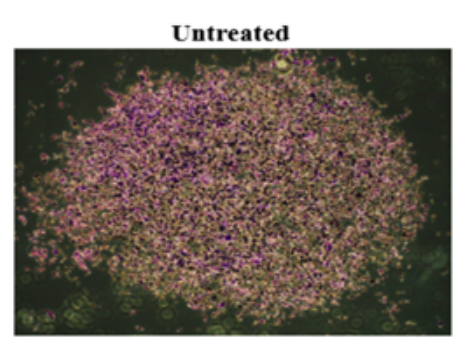

$50 \mu M$

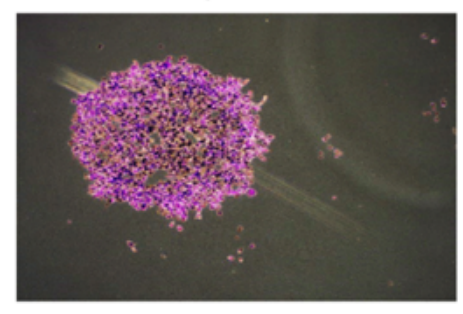

UMUC3

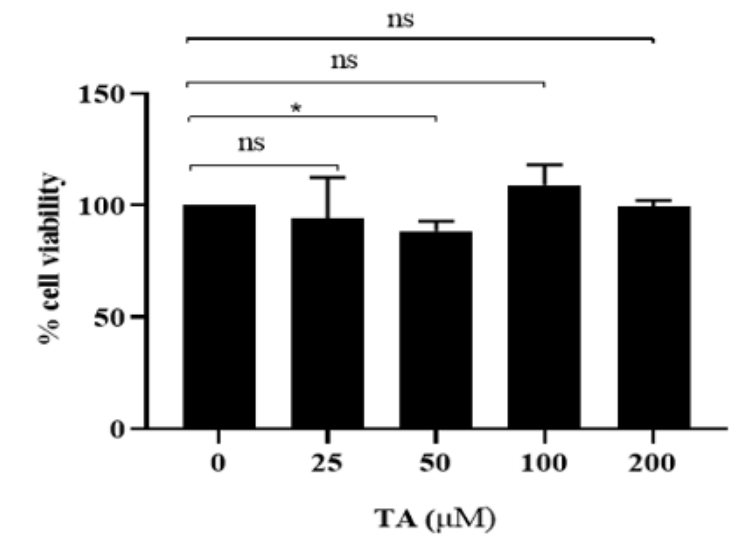

D
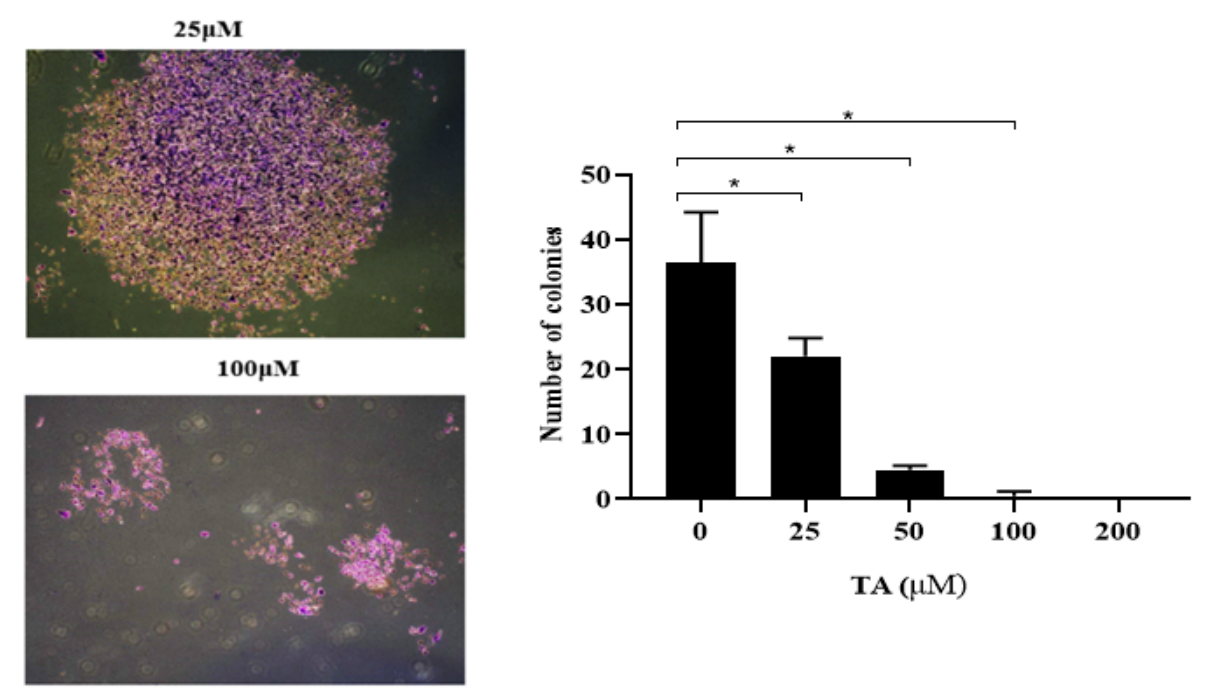

\section{Figure 1}

Anti-proliferative effect of tannic acid (TA) in invasive bladder cancer cells. A) MTT assay of UMUC3 cells after 24 hours of TA treatment. B) Immortalized normal bladder cells SV-HUC1. Cells were seeded 24 hours before treatment and were then exposed to TA at different concentrations $(0,25,50,100$, and 200 $\mu \mathrm{M})$ for 24 hours. Treated cells are presented in comparison with the untreated control. C) Colony formation of UMUC3 cells. $5 \times 102$ cells were seeded, treated with TA at different concentrations, incubated for 24 hours, washed with PBS, and analyzed after 14 days. The colony size differences, and colony numbers are shown. Results are mean of the three independent experiments. Student's t-test: Treatment vs Control $\mathrm{P}<0.05\left({ }^{*}\right)$. 


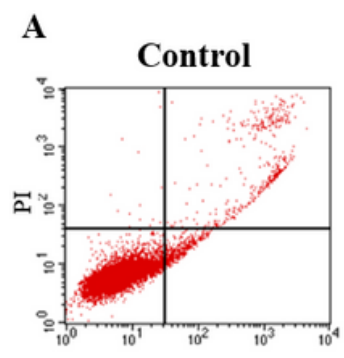

Annexin V
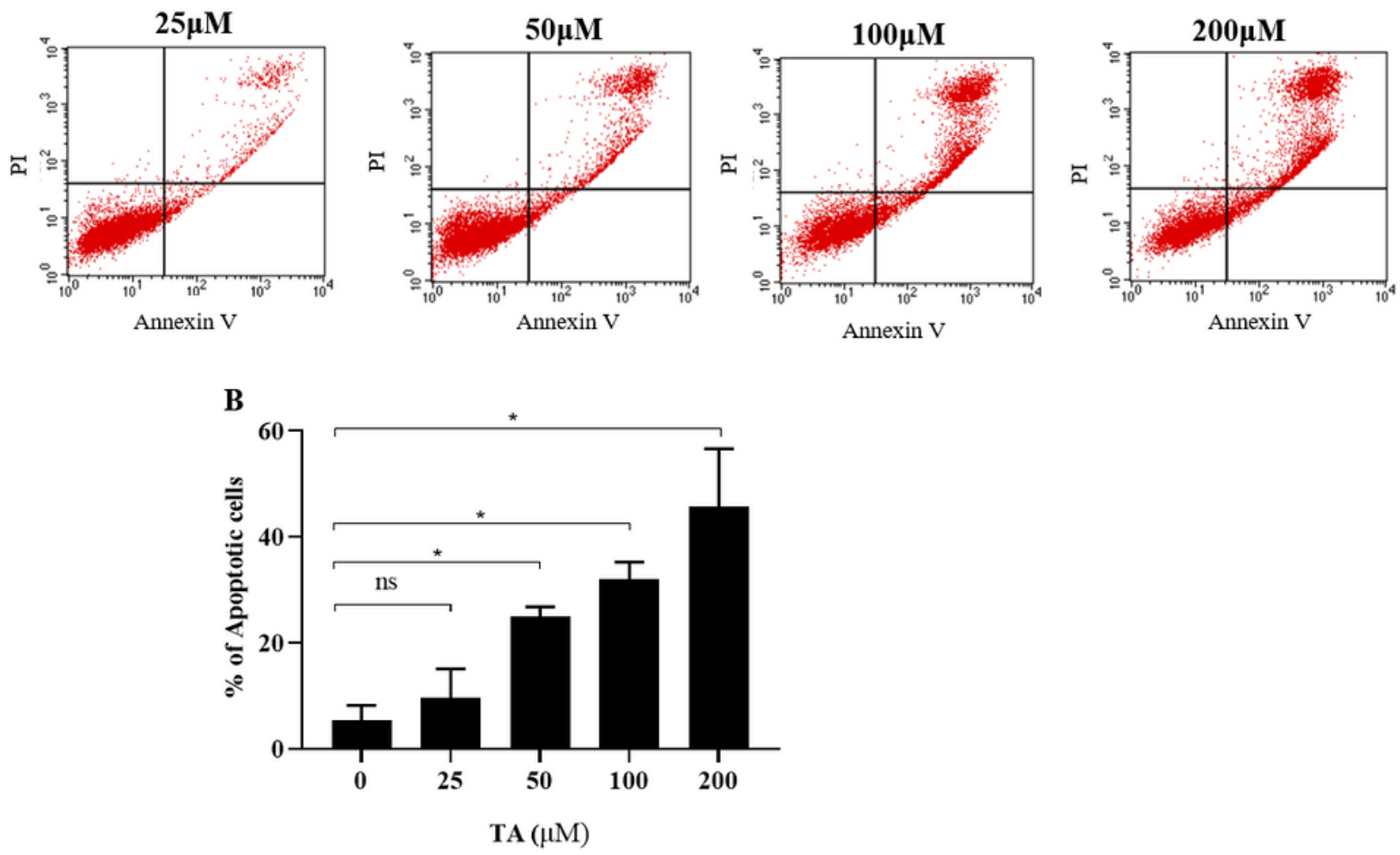

Figure 2

A) Apoptosis induced by tannic acid in UMUC3 cells. UMUC3 cells were plated in a 6-well plate and treated with control media or TA for 24 hours. The cells were trypsinzed and collected in microcentrifuge tubes. The tube was centrifuged at $1500 \mathrm{rpm}$ for 5 minutes, and $1 \times 105$ cells were counted and transferred to the flow tube. $5 \mu \mathrm{L}$ of propidium iodide and Annexin $\mathrm{V}$ were added to the cells, and they were incubated in dark for 15 minutes before analysis by FACS. B) Graphical analysis of apoptosis induced by TA treatment after 24 hours. The results are mean of three independent experiments. Student t-test Treatment vs control $\mathrm{P}<0.05\left(^{*}\right)$.

A
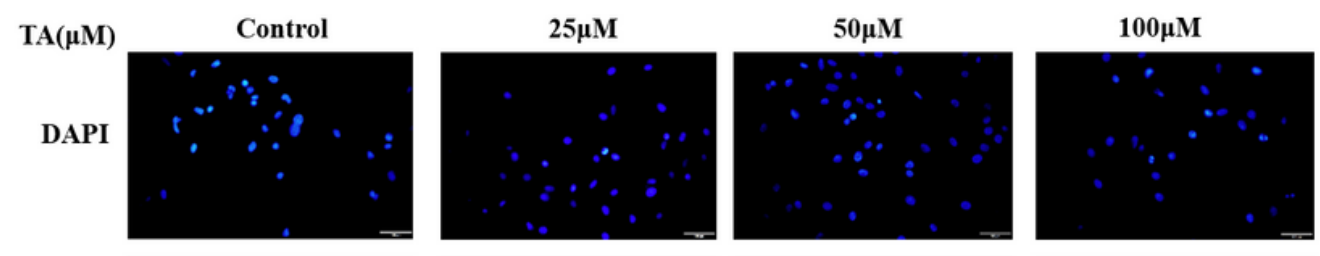

TUNEL
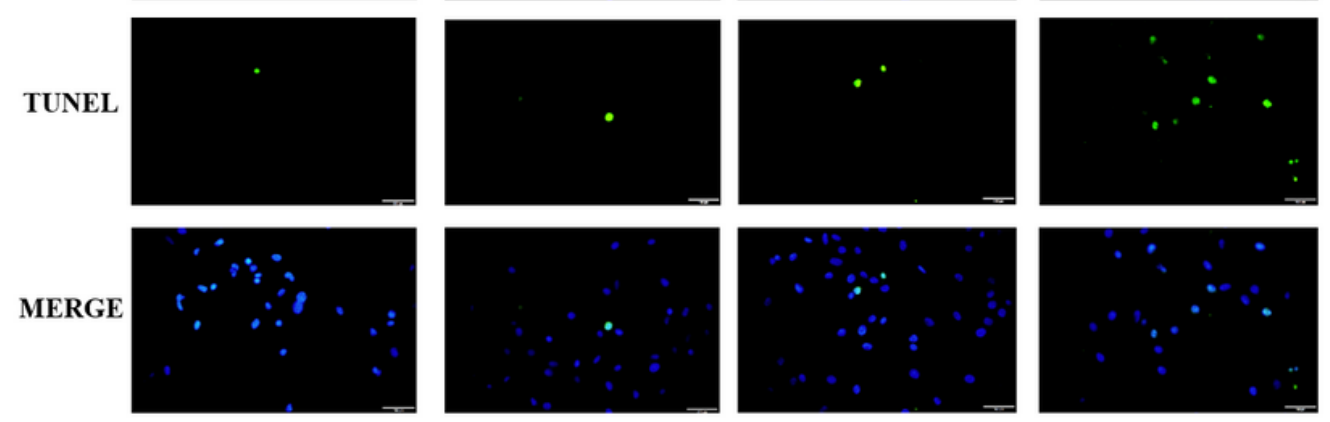

B

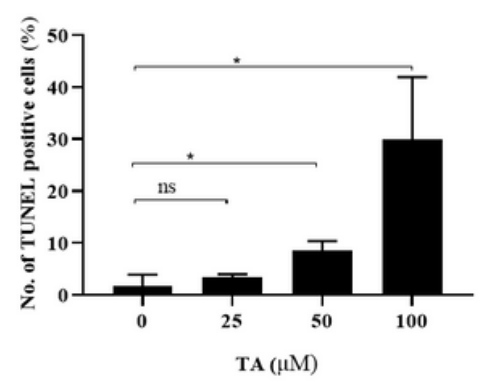

Figure 3 
A) Tunnel assay: $5 \times 103$ UMUC3 cells were seeded in an 8-well chamber and incubated to allow attachment of cells. After 24 hours, they were treated with TA and incubated for another 24 hours. Then, TA was removed and the cells were washed twice with PBS and fixed with $4 \%$ paraformaldehyde. They were then incubated for 1 hour at room temperature. Then slides were permeabilized for 1-2 minutes, followed by a wash with PBS. TUNEL reagent was added to each well and incubated for 3 hours. After washing, the slides were stained with DAPI and covered with cover slip. Fluorescence microscopy was used for analysis. B) Quantitative analysis of tunnel positive cells induced by TA treatment. The results are mean of three independent experiments. Student t-test Treatment vs control $(P<0.05)\left({ }^{*}\right)$.

A

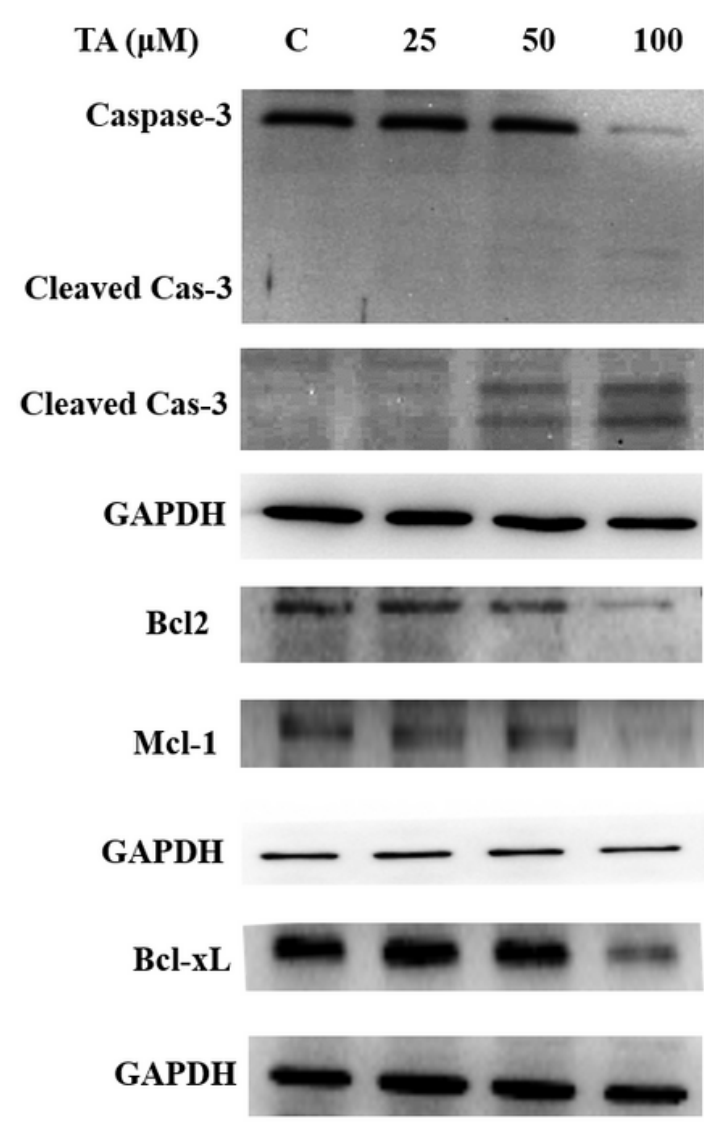

B

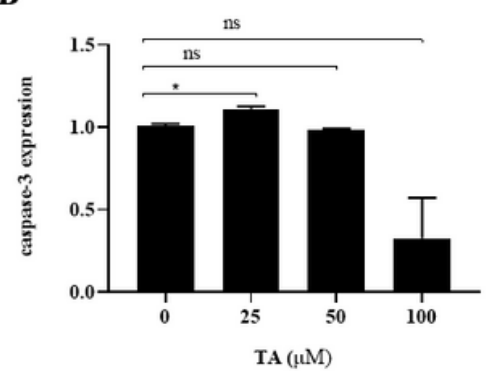

D

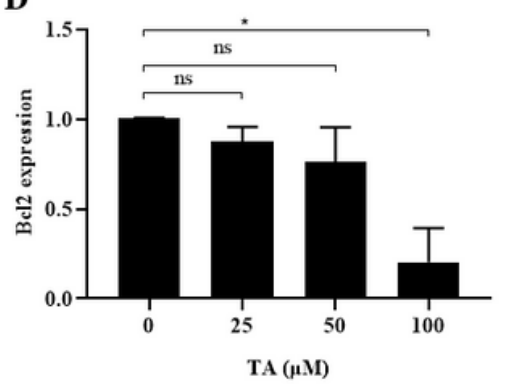

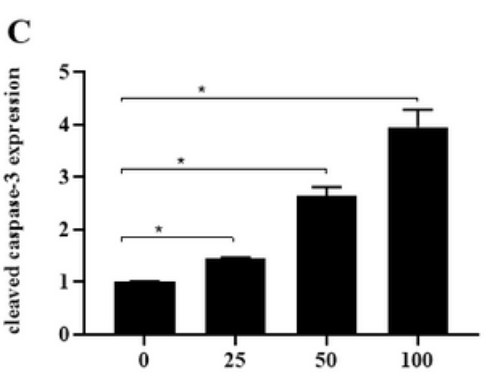

$\mathbf{E}$

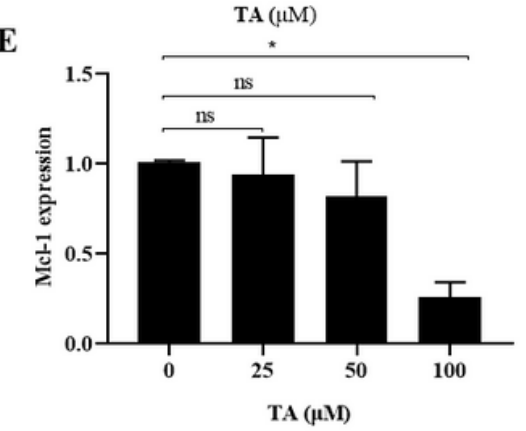

$\mathbf{F}$

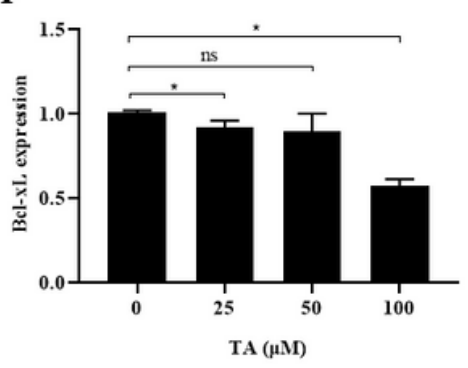

Figure 4

Tannic acid mediates mitochondrial apoptosis in UMUC3 cells A) UMUC3 cells were treated with TA for 24 hours. Proteins were isolated and protein were detected by western blot technique. Apoptotic proteins were analyzed. B) Apoptotic protein expression was normalized to GAPDH expression and the Student's ttest was performed to determine statistical significance $(P<0.05)(*)$. 
$\mathbf{A}$

$\begin{array}{lllll}\mathrm{TA}(\boldsymbol{\mu} \mathrm{M}) & \mathrm{C} & 25 & 50 & \mathbf{1 0 0}\end{array}$

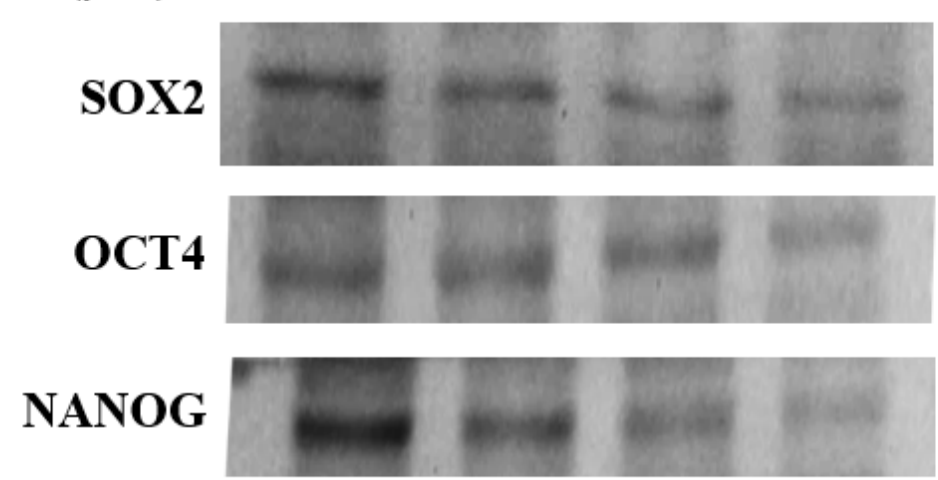

GAPDH

B

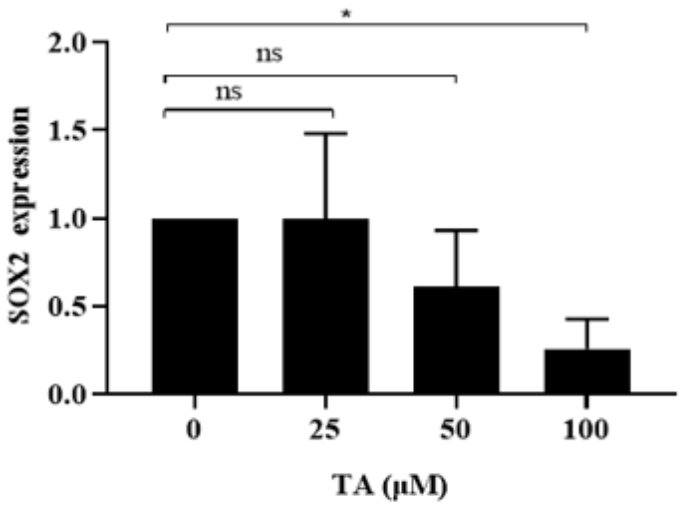

C

D
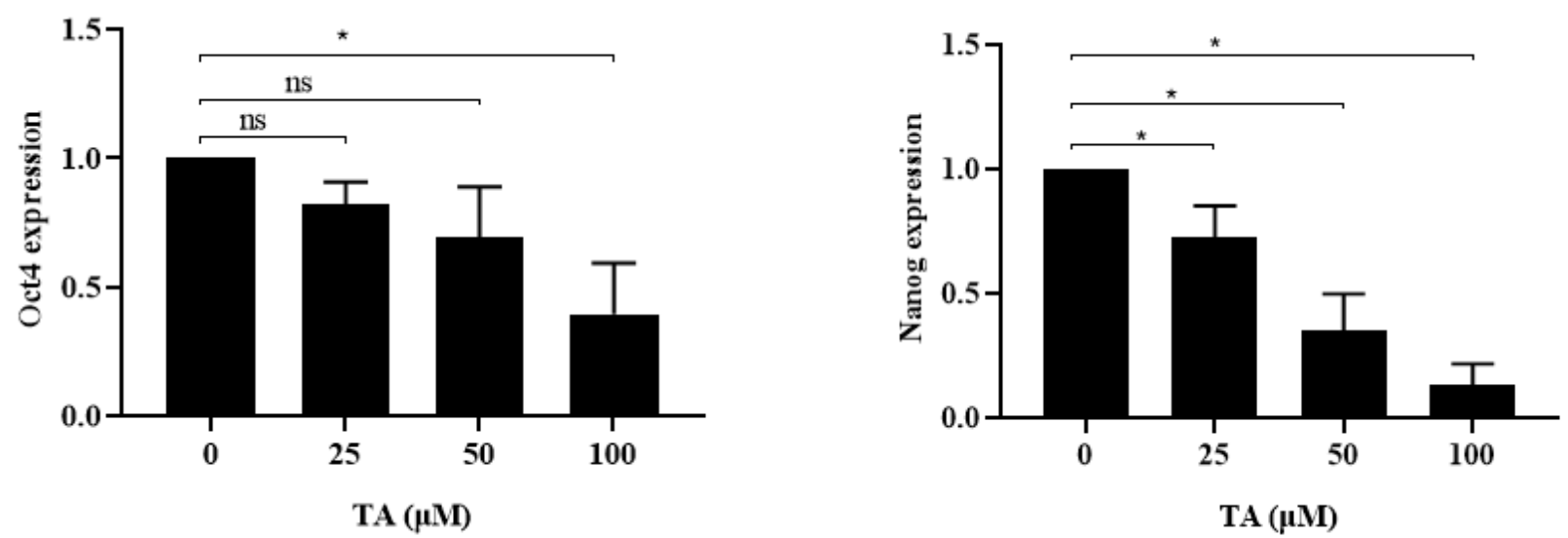

Figure 5

Tannic acid affects the stemness properties of UMUC3 cancer cells. A) UMUC3 were seeded and treated with TA for 24 hours and protein was isolated, quantified, and expression of stem cell markers such as SOX2, OCT4, and NANOG was analyzed by western blot. B) Statistical analysis of stem cell markers expression normalized to GAPDH control. Student's t-test $(P<0.05)$ represented as $\left.{ }^{*}\right)$ indicates statistical difference between the control and treatment groups. 
A
$\mathbf{T A}(\mu \mathrm{M})$
C
25
50
100

P-AKT

\section{GAPDH}
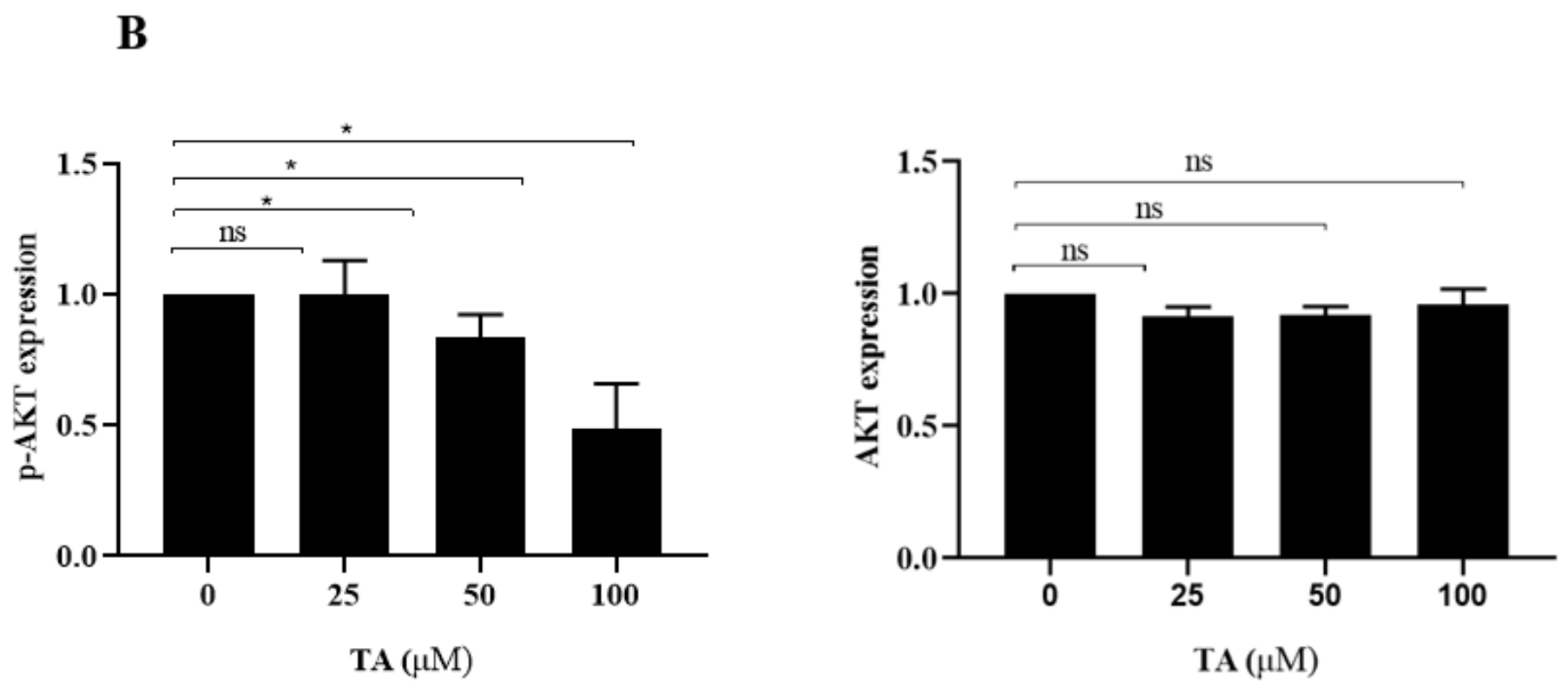

Figure 6

Tannic acid downregulates expression of PI3K/AKT signaling pathway genes: A) UMUC3 cells were treated in different concentrations of TA, and after treatment for 24 hours, the cells were harvested and the protein expression was analyzed using Western blotting. B) Statistical analysis of p-AKT and AKT expression normalized to internal control GAPDH. Student's t-test $(P<0.05)\left({ }^{*}\right)$ calculated indicates statistical difference. 